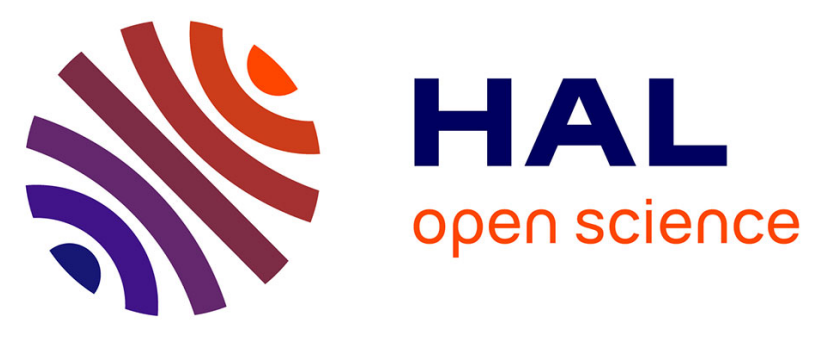

\title{
Experimental design and solid state fermentation: A holistic approach to improve cultural medium for the production of fungal secondary metabolites
}

Quentin Carboué, Magalie Claeys-Bruno, Isabelle Bombarda, Michelle Sergent, Jérôme Jolain, Sevastianos Roussos

\section{To cite this version:}

Quentin Carboué, Magalie Claeys-Bruno, Isabelle Bombarda, Michelle Sergent, Jérôme Jolain, et al.. Experimental design and solid state fermentation: A holistic approach to improve cultural medium for the production of fungal secondary metabolites. Chemometrics and Intelligent Laboratory Systems, 2018, 176, pp.101 - 107. 10.1016/j.chemolab.2018.03.011 . hal-01930229

\section{HAL Id: hal-01930229 \\ https://hal-amu.archives-ouvertes.fr/hal-01930229}

Submitted on 21 Nov 2018

HAL is a multi-disciplinary open access archive for the deposit and dissemination of scientific research documents, whether they are published or not. The documents may come from teaching and research institutions in France or abroad, or from public or private research centers.
L'archive ouverte pluridisciplinaire HAL, est destinée au dépôt et à la diffusion de documents scientifiques de niveau recherche, publiés ou non, émanant des établissements d'enseignement et de recherche français ou étrangers, des laboratoires publics ou privés.

\section{(c)(1)}

Distributed under a Creative Commons Attribution| 4.0 International License 


\title{
Experimental design and solid state fermentation: A holistic approach to improve cultural medium for the production of fungal secondary metabolites
}

\author{
Quentin Carboué $^{\mathrm{a}, \mathrm{b}, *}$, Magalie Claeys-Bruno ${ }^{\mathrm{b}}$, Isabelle Bombarda ${ }^{\mathrm{b}}$, Michelle Sergent ${ }^{\mathrm{b}}$, \\ Jérôme Jolain $^{\mathrm{b}}$, Sevastianos Roussos ${ }^{\mathrm{b}}$ \\ a Vinovalie, PA les Xansos, 81600 Brens, France \\ ${ }^{\mathrm{b}}$ Aix Marseille Univ, Univ Avignon, CNRS, IRD, IMBE, Marseille, France
}

Keywords:

Solid-state fermentation

Experimental design

Aspergillus niger

Naphtho-gamma-pyrones

\begin{abstract}
A B S T R A C T
Solid-state fermentation (SSF) is a cultural method that holds tremendous potentials for the production of numerous microbial value-added compounds in various industries. As for every other process, experimental designs can provide tools to improve the product yields, diminish the production time and thus eventually decreasing the cost of the whole process. However, SSF, because of its solid nature, implies some constraints which consequently require specific tools to efficiently overcome them. The aim of this study was the improvement of the production of antioxidant naphtho-gamma-pyrones produced by Aspergillus niger G131 cultivated using SSF. Two experimental designs were presented, a combined design, taking into account two different types of variables to determine a proper solid medium, and a screening design with mixed-level factors to find solutes with significant positive effects on the output.
\end{abstract}

\section{Introduction}

Solid-state fermentation (SSF) is defined as the fermentation involving solids in absence (or near absence) of free water; however, substrate must possess enough moisture to support growth and metabolism of microorganisms [1]. The SSF system offers several economical and practical advantages including high product concentration, improvement of product recovery, simple cultivation equipment, lower plant operational, potential direct utilization of the crude fermented products and also the possibility to use agro-industrial byproducts instead of synthetic ingredients as substrate, thereby to cost cutting the bulk of the production [2,3]. These solid byproducts could be either a source of carbon and other nutrients or an inert support material for absorption of nutrients and biomass anchorage. In this case, supplementation is needed in order to provide all necessary compounds for an optimum growth. Macro and micronutrients that are usually added to the medium include phosphorus, sulfur, potassium, magnesium, calcium, zinc, manganese, copper, iron, cobalt, and iodine [4,5]. Each microorganism has its own optimal cultivation conditions and requires specific substrates depending on the expected products. Optimization of the medium and cultural conditions is hence essential step to maximize the production, especially if the process heads towards industrial scale. Most SSF bioprocess optimization studies use response surface methodology (RSM), which is a powerful statistical and mathematical method for testing multiple process variables and their interactions simultaneously with limited experimental trials compared to "one-factor-at-a-time" approach [6]. However, these optimizations are always achieved on a defined solid medium, selected using a classical one-factor-at-a-time approach. Indeed most of these studies use only one substrate as a basal solid medium, comparing effects of each substrate separately; resulting that the best solid substrate is fixed for subsequent experiments. In consequence, most studies investigate with precision the effects of chemical complementation with soluble compounds and physical parameters such as temperature and humidity but neglecting the definition of a proper solid medium [2,7-12]. In this study we investigated the medium optimization using a holistic strategy, to improve the production of naphtho-gamma-pyrones ( $\mathrm{N} \gamma \mathrm{Ps})$ - secondary metabolites showing interesting antioxidant properties - by Aspergillus niger G131 cultivated on solid support. First, the solid medium composition was defined using combined designs - with mixture and discrete variables - and then the

\footnotetext{
* Corresponding author. Vinovalie, PA les Xansos, 81600 Brens, France.

E-mail address: quentin.carboue.qc@gmail.com (Q. Carboué).
} 
chemical complementation was made using an asymmetric screening design that answer efficiently to the constraints imposed by SSF.

\section{Materials and methods}

\subsection{Strain}

A. niger G131, a non-ochratoxicogenic strain, provided by École nationale supérieure agronomique de Toulouse, France was used for its ability to produce antioxidant $\mathrm{N} \gamma \mathrm{Ps}$ such as fonsecin, fonsecin $\mathrm{B}$ and ustilaginoidin A.

\subsection{Inoculum}

The fungal strain was conserved at $4{ }^{\circ} \mathrm{C}$ in a $5 \mathrm{ml}$ bottle on potato dextrose agar (PDA). The inoculum stock was prepared by propagating the fungus in Erlenmeyer flasks containing PDA. The cultures were incubated at $25^{\circ} \mathrm{C}$ for $5-10$ days. The inoculum suspension was prepared by adding $0.01 \%(\mathrm{v} / \mathrm{v})$ Tween 80 and scraping with a magnetic stirrer to recover the conidia. The quantity of conidia was counted using a Malassez cell prior to inoculation of the solid medium.

\subsection{Solid-state fermentation}

Fungal growth was performed in flask on $5 \mathrm{~g}$ (dry mass) of solid substrate, at $25{ }^{\circ} \mathrm{C}$ in a lab oven, at $66 \%$ of initial humidity and during 7 days. The initial inoculation rate was $2.10^{7}$ conidias/g dry matter. Each modality presented in this study was realized in triplicate.

\subsection{Determination of the dry weight of the sample}

The results presented in this article are expressed in dry weight. To determine the dry weight of a sample, $1 \mathrm{~g}$ of moist fermented material was put in an oven at $105^{\circ} \mathrm{C}$ during $24 \mathrm{~h}$ and was reweighted to measure the percentage of lost water.

\subsection{Extraction and analysis of $\mathrm{N} \gamma \mathrm{PS}$}

To analyze the $\mathrm{N} \gamma \mathrm{Ps}$ produced by the fungus, $1 \mathrm{~g}$ of moist fermented material was taken from each flask and mixed with $10 \mathrm{ml}$ of analytical ethanol during $1 \mathrm{~h}$. The obtained ethanolic extract was then filtered with $0.2 \mu \mathrm{m}$ Millipore filter prior to high performance liquid chromatography (HPLC) analysis. The HPLC system (Agilent Technologies ${ }^{\circledR}$, Santa Clara, USA) was equipped with a diode array detector, a RP18 analytical column $(150 \times 4.6 \mathrm{~mm}, 5 \mu \mathrm{m}$ particle size, Zorbax Eclipse XDB, Agilent Technologies $^{\odot}$ ), fitted to a RP18 guard column $\left(10 \times 4 \mathrm{~mm}\right.$, Agilent, Santa Clara, USA) and kept at $30^{\circ} \mathrm{C}$ during the analysis. The crude $\mathrm{N} \gamma \mathrm{P}$ extracts $(40 \mu \mathrm{L})$ were injected using an autosampler. The mobile phase consisted of acidified water $(0.2 \%$ glacial acetic acid) (A) and acetonitrile (B). The linear gradient started from $30 \%$ to $100 \%$ of B during $45 \mathrm{~min}$, then $100 \%$ B for $5 \mathrm{~min}$ at a flow rate of $1 \mathrm{ml} \mathrm{min}-1$, The N $\gamma$ Ps were monitored at $280 \mathrm{~nm}$ and the concentrations obtained from subsequent peaks were calculated using ChemStation B.02.01 (Agilent Technologies ${ }^{\circledR}$ ). For a $\mathrm{N} \gamma \mathrm{P}$ peak, the concentration was determined using the commercial standard rubrofusarin A (BiovioticaNaturstoffe $\mathrm{GmbH}$, Germany). The results were expressed in $\mathrm{mg}$ equivalent rubrofusarin/g dry matter based on the calibration curve obtained from the analysis of standard solutions ranging from 2 to $200 \mathrm{mg} / \mathrm{l}$. Rubrofusarin $\mathrm{A}$ has been chosen as calibrant in this study because it is one of the few commercial $\mathrm{N} \gamma \mathrm{P}$ available on the market. For a given sample, the response variable, "found $\mathrm{N} \gamma \mathrm{Ps}$ content" corresponds to the whole production of N $\gamma \mathrm{Ps}$, calculated as the total of each $\mathrm{N} \gamma \mathrm{P}$ produced. Fig. 1 shows a chromatogram with the $\mathrm{N} \gamma \mathrm{Ps}$ found in the extract. Growing on a solid medium composed by vegetal substrates, the fungus also releases valuable molecules from the solid matrix during his hydrolytic activity like trans-p-coumaric acid and trans-ethyl-ferulate. For the purpose of simplicity and because of their non-negligible participation in the general antioxidant activity of the ethanolic extract and the fact that their maximum of UV absorption is like the $\mathrm{N} \gamma \mathrm{Ps}$, at $280 \mathrm{~nm}$, trans-p-coumaric acid and trans-ethyl-ferulate are treated like N $\gamma$ Ps in this study.

\subsection{Design of experiments}

\subsubsection{Determination of the solid medium}

\section{- Factors and domain of interest}

To determine the optimum composition of the solid-medium for the production of $\mathrm{N} \gamma \mathrm{Ps}$, we studied the behavior of 3 substrates in the formula - wheat bran, olive pomace and potato flakes, (each component $X_{1}$, $\mathrm{X}_{2}$ and $\mathrm{X}_{3}$ varying between 0 and $100 \%$ ) - and the nature of the solid support - vine shoots and pine sawdust. Wheat bran has been selected as a potential protein source, olive pomace as a lipid source and potato flakes as a starch source. The experimental domain of interest is shown Table 1.

For this modelization, we should have performed experiments in the whole experimental domain, which represents an infinite number of formulas which is of course unthinkable. Therefore, we have used an empirical mathematical model to represent the phenomenon in the domain of interest. This model based on four predictor variables was built as follows:

- The three mixture variables $\left(\mathrm{X}_{1}, \mathrm{X}_{2}, \mathrm{X}_{3}\right)$ are described with a reduced cubic model in the component fractions [13]. $\eta_{\mathrm{m}}=\beta_{1} \mathrm{X}_{1}+\beta_{2} \mathrm{X}_{2}+\beta_{3} \mathrm{X}_{3}+\beta_{12} \mathrm{X}_{1} \mathrm{X}_{2}+\beta_{13} \mathrm{X}_{1} \mathrm{X}_{3}+\beta_{23} \mathrm{X}_{2} \mathrm{X}_{3}+\beta_{123} \mathrm{X}_{1} \mathrm{X}_{2} \mathrm{X}_{3}$

- The discrete variable $\left(X_{4}\right)$ is described using polynomial model (degree 1)

Finally, the complete model describing the production of N $\gamma$ Ps was a multiplicative particular model (only the degree 2 multiplicative terms have been selected plus the mixture cubic term) in order to take into

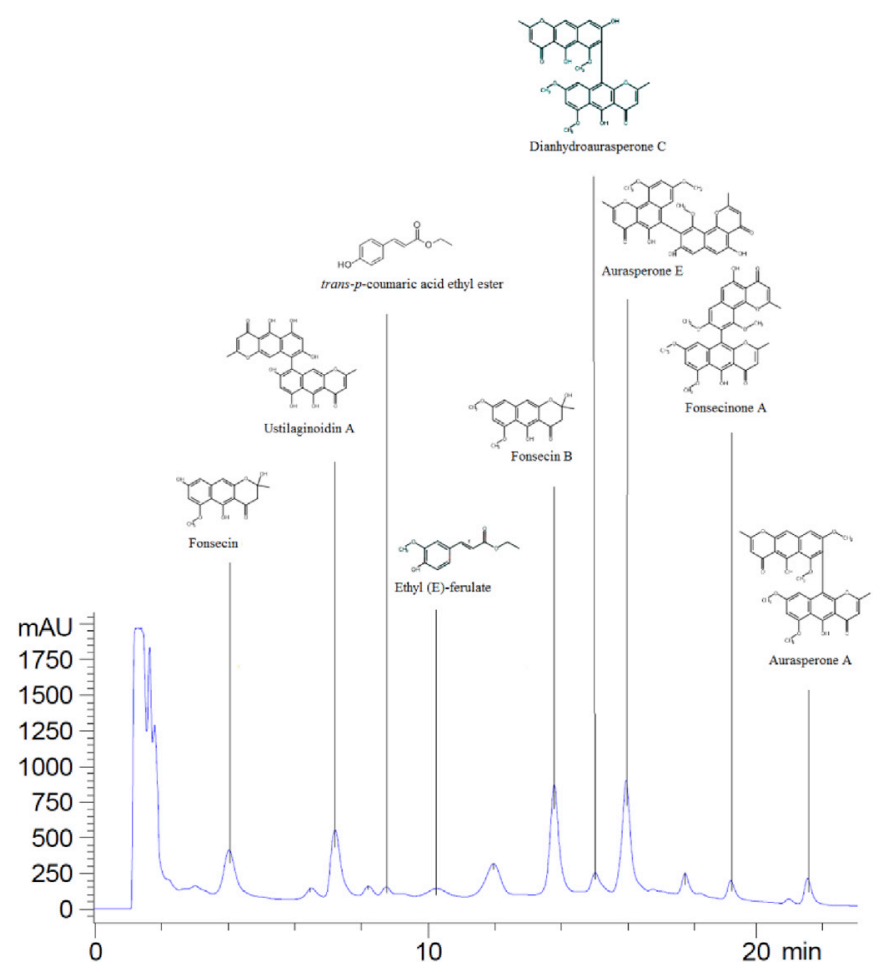

Fig. 1. Chromatogram of an ethanolic extract. The structures of molecules are associated with the peaks. 
Table 1

Factors and experimental domain of interest for the solid medium definition.

- Mathematical modeling

\begin{tabular}{llll}
\hline Variables & & Experimental domain \\
\hline Mixture variables & $\mathrm{X}_{1}$ Wheat bran & $0 \% \rightarrow 100 \%$ & \\
& $\mathrm{X}_{2}$ Olive pomace & & \\
& $\mathrm{X}_{3}$ Potato flakes & & \\
Discrete variable & $\mathrm{X}_{4}$ Support nature & Vine shoot & Pine sawdust \\
\hline
\end{tabular}

account the interactions between the discrete variable and the mixture variables.

$$
\begin{aligned}
& \eta=\beta_{1} X_{1}+\beta_{2} X_{2}+\beta_{3} X_{3}+\beta_{12} X_{1} X_{2}+\beta_{13} X_{1} X_{3}+\beta_{23} X_{2} X_{3}+\beta_{123} X_{1} X_{2} X_{3} \\
& +\beta_{14} X_{1} X_{4}+\beta_{24} X_{2} X_{4}+\beta_{34} X_{3} X_{4}
\end{aligned}
$$

In order to estimate the mathematical model coefficients, experiments were carefully chosen since classical design of experiments could not be used.

\section{- Construction of the experimental design}

To estimate the coefficients of this model a specific design of experiments was built. In a first step, 32 candidate points have been generated to cover the set of possible experiments. To reduce the number of experiments, a D-optimal design was chosen. This design was built using the exchange algorithm proposed by Fedorov [14]. In this case, the function of variance was chosen as the acceptability criterion. 14 experiments have been selected as shown in Fig. 2. In order to validate the model, 2 test points have been added.

\subsubsection{Determination of the chemical complementation}

A screening study was realized to determine the right optimum complementation of the previously defined solid medium.

\section{- Factors and domain of interest}

The influence of 11 variables on the N $\gamma$ Ps production was studied: 9 variables with 2 levels and 2 variables with 3 levels (Table 2).

The levels are expressed as a percentage of the initial dry matter.

\section{- Mathematical modeling}

In this screening study, the effects of factors were supposed to be additive. This hypothesis implied that all the interaction effects were negligible. In our case, mixed-level factors were studied and we postulated that the production of $\mathrm{N} \gamma \mathrm{Ps}$ was a linear combination of the effect coded variables $\mathrm{X}_{1 \mathrm{~A}}, \mathrm{X}_{2 \mathrm{~A}}, \ldots, \mathrm{X}_{11 \mathrm{~B}}$. The reduced reference state model used for 9 factors with 2 levels and 2 factors with 3 levels is expressed as

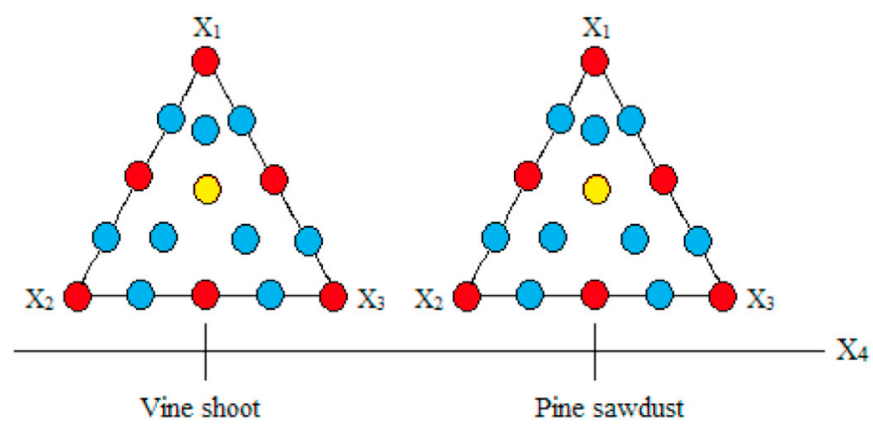

Fig. 2. Selected points to estimate the model coefficients. In blue the candidate points, in red the selected points and in yellow the selected test points. (For interpretation of the references to color in this figure legend, the reader is referred to the Web version of this article.)
Table 2

Factors and domain of interest for the chemical complementations.

\begin{tabular}{llll}
\hline Variables & Level 1 & Level 2 & Level 3 \\
\hline $\mathrm{X}_{1}$ Sodium nitrate & 0 & 1.5 & \\
$\mathrm{X}_{2}$ Benzoic acid & 0 & 0.5 & \\
$\mathrm{X}_{3}$ Ammonium molybdate & 0 & 0.2 & \\
$\mathrm{X}_{4}$ Manganese sulfate & 0 & 0.2 & \\
$\mathrm{X}_{5}$ Zinc sulfate & 0 & 0.2 & \\
$\mathrm{X}_{6}$ Ammonium sulfate & 0 & 1.5 & \\
$\mathrm{X}_{7}$ Glucose & 0 & 2 & \\
$\mathrm{X}_{8}$ Potassium phosphate & 0 & 0.5 & \\
$\mathrm{X}_{9}$ Hydrogen peroxide & 0 & 0.34 & 0.2 \\
$\mathrm{X}_{10}$ Copper sulfate & 0 & 0.05 & \\
$\mathrm{X}_{11}$ Magnesium chloride & 0 & 0.05 & \\
\hline
\end{tabular}

following:

$\eta=\beta_{0}+\beta_{1 \mathrm{~A}} \mathrm{X}_{1 \mathrm{~A}}+\beta_{2 \mathrm{~A}} \mathrm{X}_{2 \mathrm{~A}}+\beta_{3 \mathrm{~A}} \mathrm{X}_{3 \mathrm{~A}}+\ldots+\beta_{9 \mathrm{~A}} \mathrm{X}_{9 \mathrm{~A}}+\beta_{10 \mathrm{~A}} \mathrm{X}_{10 \mathrm{~A}}+\beta_{10 \mathrm{~B}} \mathrm{X}_{10 \mathrm{~B}}$ $+\beta_{11 \mathrm{~A}} \mathrm{X}_{11 \mathrm{~A}}+\beta_{11 \mathrm{~B}} \mathrm{X}_{11 \mathrm{~B}}$

Table 3

Conditions runs of the combined design in 14 experiments plus 2 test points and

\begin{tabular}{|c|c|c|c|c|c|}
\hline Run & $\mathrm{X}_{1}$ & $\mathrm{X}_{2}$ & $\mathrm{X}_{3}$ & $\mathrm{X}_{4}$ & Found $\mathrm{N} \gamma \mathrm{Ps}$ content $\mathrm{a}^{\mathrm{a}}$ \\
\hline \multirow[t]{3}{*}{1} & 1.00 & 0.00 & 0.00 & Vine shoot & 0.954 \\
\hline & & & & & 0.765 \\
\hline & & & & & 0.953 \\
\hline \multirow[t]{3}{*}{2} & 0.00 & 1.00 & 0.00 & Vine shoot & 0.207 \\
\hline & & & & & 0.345 \\
\hline & & & & & 0.343 \\
\hline \multirow[t]{3}{*}{3} & 0.00 & 0.00 & 1.00 & Vine shoot & 3.951 \\
\hline & & & & & 3.642 \\
\hline & & & & & 3.549 \\
\hline \multirow[t]{3}{*}{4} & 0.50 & 0.50 & 0.00 & Vine shoot & 1.724 \\
\hline & & & & & 2.038 \\
\hline & & & & & 2.456 \\
\hline \multirow[t]{3}{*}{5} & 0.50 & 0.00 & 0.50 & Vine shoot & 3.502 \\
\hline & & & & & 3.072 \\
\hline & & & & & 3.121 \\
\hline \multirow[t]{3}{*}{6} & 0.00 & 0.50 & 0.50 & Vine shoot & 1.014 \\
\hline & & & & & 1.211 \\
\hline & & & & & 1.504 \\
\hline \multirow[t]{3}{*}{7} & 0.33 & 0.33 & 0.33 & Vine shoot & 2.717 \\
\hline & & & & & 2.548 \\
\hline & & & & & 2.664 \\
\hline \multirow[t]{3}{*}{$8^{\mathrm{b}}$} & 0.17 & 0.17 & 0.66 & Vine shoot & 2.926 \\
\hline & & & & & 3.461 \\
\hline & & & & & 3.160 \\
\hline \multirow[t]{3}{*}{9} & 1.00 & 0.00 & 0.00 & Pine sawdust & 0.782 \\
\hline & & & & & 0.888 \\
\hline & & & & & 0.853 \\
\hline \multirow[t]{3}{*}{10} & 0.00 & 1.00 & 0.00 & Pine sawdust & 0.245 \\
\hline & & & & & 0.267 \\
\hline & & & & & 0.377 \\
\hline \multirow[t]{3}{*}{11} & 0.00 & 0.00 & 1.00 & Pine sawdust & 3.811 \\
\hline & & & & & 4.254 \\
\hline & & & & & 3.614 \\
\hline \multirow[t]{3}{*}{12} & 0.50 & 0.50 & 0.00 & Pine sawdust & 2.010 \\
\hline & & & & & 1.949 \\
\hline & & & & & 1.949 \\
\hline \multirow[t]{3}{*}{13} & 0.50 & 0.00 & 0.50 & Pine sawdust & 3.022 \\
\hline & & & & & 3.904 \\
\hline & & & & & 3.454 \\
\hline \multirow[t]{3}{*}{14} & 0.00 & 0.50 & 0.50 & Pine sawdust & 2.016 \\
\hline & & & & & 1.797 \\
\hline & & & & & 1.726 \\
\hline \multirow[t]{3}{*}{15} & 0.33 & 0.33 & 0.33 & Pine sawdust & 3.412 \\
\hline & & & & & 2.976 \\
\hline & & & & & 3.661 \\
\hline \multirow[t]{3}{*}{$16^{\mathrm{b}}$} & 0.66 & 0.17 & 0.17 & Pine sawdust & 2.337 \\
\hline & & & & & 2.015 \\
\hline & & & & & 2.216 \\
\hline
\end{tabular}
their values of the response "found N $\gamma$ Ps content".

${ }^{\text {a }}$ Found $\mathrm{N} \gamma \mathrm{Ps}$ content in mg equivalent rubrofusarine/g of dry matter.

b Test point. 
$\beta_{1 \mathrm{~A}}, \ldots, \beta_{9 \mathrm{~A}}$ represent the value of the factor differential effect, i.e. the variation of the response when the factor changes from level B taken as reference to level $\mathrm{A}, \beta_{10 \mathrm{~A}}$ and $\beta_{10 \mathrm{~B}}$ and $\beta_{11 \mathrm{~A}}$ and $\beta_{11 \mathrm{~B}}$ represent the variation of the response when the factor changes from level $\mathrm{C}$ taken as reference to levels $\mathrm{A}$ and $\mathrm{B}$ respectively.

\section{- Construction of the experimental design}

The model having 14 coefficients, an asymmetric design $2^{9} 3^{2}$ with 16 experiments was built from the optimal symmetrical design $45 / / 16$ using the Addelman's correspondence method [15]. This allows the construction of asymmetrical design from symmetrical ones by collapsing columns, either by replacing a column by another with fewer levels or by replacing a single four-levels column by three two-levels columns.

\subsection{Statistical analysis}

The generation and the data treatment of the designs were performed using the software Nemrod-W [16].

\section{Results and discussion}

\subsection{Determination of the solid medium}

The 14 experiments for the model construction were done and the results are given in Table 3. Moreover, the observation of the different replicates indicates that each experiment presents a low variability based on the observation of the proximity of the points of the same color (Fig. 3).

The calculated values of the model coefficients are given in Table 4.

The model validation was performed using a $t$-test on the difference between experimental values and predicted values for the 2 test points (Table 5).

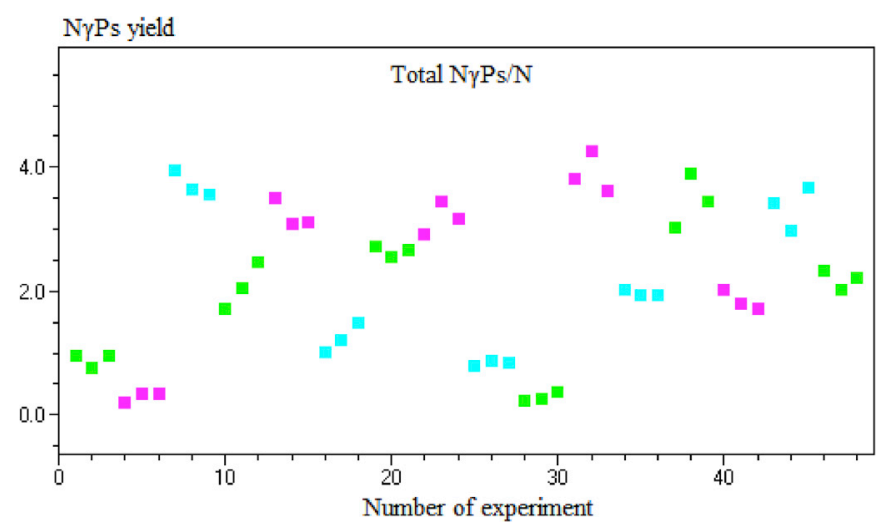

Fig. 3. Repeatability of the experiments for the medium definition. Triplicates of the same experiment are of same color. (For interpretation of the references to color in this figure legend, the reader is referred to the Web version of this article.)
Table 5

Validation of the model using the 2 test points.

\begin{tabular}{lll}
\hline Experimental response & Calculated response & Difference \\
\hline 2.926 & 3.18 & -0.25 \\
3.461 & & 0.28 \\
3.160 & & -0.02 \\
2.337 & 2.59 & -0.25 \\
2.015 & & -0.57 \\
2.216 & & -0.37 \\
\hline
\end{tabular}

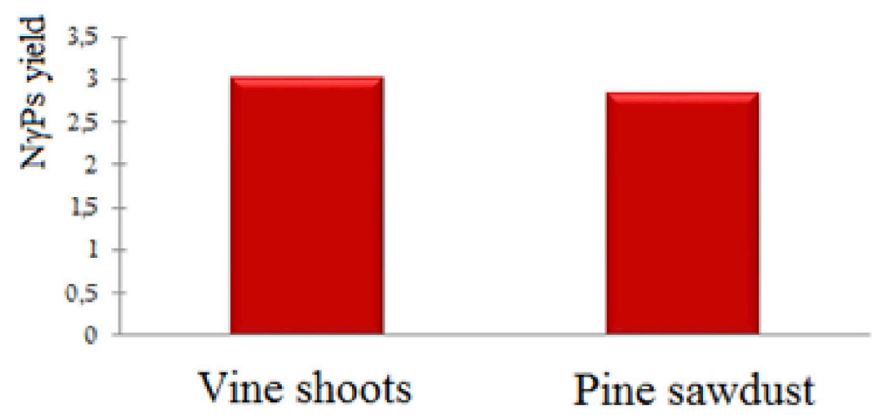

Fig. 4. Effect of the discrete variable $\mathrm{X}_{4}$.

The difference between the calculated and the experimental values show no significant difference using a $t$-test $(\alpha=5 \%)$. Thus the model can be applied for prediction using the 16 experiments.

The effect of $\mathrm{X}_{4}$ has been calculated for $\mathrm{X}_{1}=33 \%, \mathrm{X}_{2}=33 \%$ and $\mathrm{X}_{3}=33 \%$, it appeared that the nature of the support to carry the fermentation had no significant effect on the response variable; indeed the found $\mathrm{N} \gamma \mathrm{Ps}$ contents are the same whether vine shoots or pine sawdust were used (Fig. 4).

Fig. 5 shows a three-dimensional diagram (a) and a contour plot of the calculated response surface (b). The optimum ratio to maximize $\mathrm{N} \gamma \mathrm{Ps}$

\section{a}

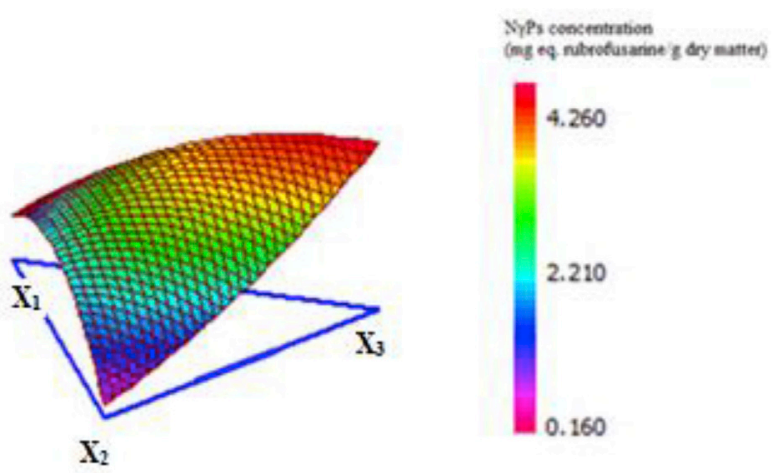

$\mathrm{b}$

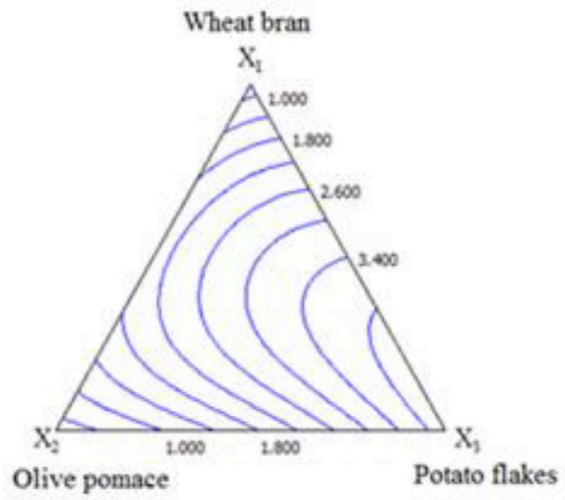

Fig. 5. Effect of the mixture variables on the N $\gamma \mathrm{Ps}$ production. 
Table 6

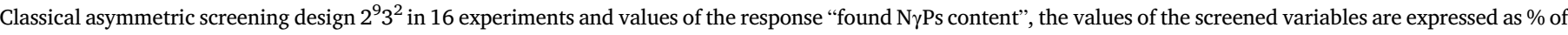
dry matter.

\begin{tabular}{|c|c|c|c|c|c|c|c|c|c|c|c|c|}
\hline Run & $\mathrm{X}_{1}$ & $\mathrm{X}_{2}$ & $\mathrm{X}_{3}$ & $\mathrm{X}_{4}$ & $\mathrm{X}_{5}$ & $\mathrm{X}_{6}$ & $\mathrm{X}_{7}$ & $\mathrm{X}_{8}$ & $\mathrm{X}_{9}$ & $\mathrm{X}_{10}$ & $\mathrm{X}_{11}$ & Found $\mathrm{N} \gamma \mathrm{Ps}$ content $\mathrm{a}^{\mathrm{a}}$ \\
\hline \multirow[t]{3}{*}{1} & 0 & 0 & 0 & 0 & 0 & 0 & 0 & 0 & 0 & 0 & 0 & 3.777 \\
\hline & & & & & & & & & & & & 3.613 \\
\hline & & & & & & & & & & & & 3.220 \\
\hline \multirow[t]{2}{*}{2} & 0 & 0 & 0 & 0.2 & 0 & 1.5 & 2 & 0 & 0.34 & 0.05 & 0.05 & 3.673 \\
\hline & & & & & & & & & & & & 3.918 \\
\hline \multirow[t]{3}{*}{3} & 0 & 0 & 0 & 0 & 0.2 & 1.5 & 0 & 0.5 & 0.34 & 0.2 & 0.2 & 1.933 \\
\hline & & & & & & & & & & & & 1.734 \\
\hline & & & & & & & & & & & & 2.488 \\
\hline \multirow[t]{3}{*}{4} & 0 & 0 & 0 & 0.2 & 0.2 & 0 & 2 & 0.5 & 0 & 0 & 0 & 3.570 \\
\hline & & & & & & & & & & & & 2.466 \\
\hline & & & & & & & & & & & & 3.073 \\
\hline \multirow[t]{3}{*}{5} & 1.5 & 0 & 0.2 & 0 & 0 & 0 & 2 & 0 & 0.34 & 0.2 & 0 & 2.111 \\
\hline & & & & & & & & & & & & 2.377 \\
\hline & & & & & & & & & & & & 3.008 \\
\hline \multirow[t]{3}{*}{6} & 1.5 & 0 & 0.2 & 0.2 & 0 & 1.5 & 0 & 0 & 0 & 0 & 0.2 & 0.810 \\
\hline & & & & & & & & & & & & 0.929 \\
\hline & & & & & & & & & & & & 1.230 \\
\hline \multirow[t]{3}{*}{7} & 1.5 & 0 & 0.2 & 0 & 0.2 & 1.5 & 2 & 0.5 & 0 & 0 & 0.05 & 1.396 \\
\hline & & & & & & & & & & & & 0.859 \\
\hline & & & & & & & & & & & & 1.531 \\
\hline \multirow[t]{3}{*}{8} & 1.5 & 0 & 0.2 & 0.2 & 0.2 & 0 & 0 & 0.5 & 0.34 & 0.05 & 0 & 2.978 \\
\hline & & & & & & & & & & & & 1.861 \\
\hline & & & & & & & & & & & & 1.853 \\
\hline \multirow[t]{3}{*}{9} & 0 & 0.5 & 0.2 & 0 & 0 & 0 & 0 & 0.5 & 0.34 & 0 & 0.05 & 2.180 \\
\hline & & & & & & & & & & & & 2.771 \\
\hline & & & & & & & & & & & & 3.036 \\
\hline \multirow[t]{3}{*}{10} & 0 & 0.5 & 0.2 & 0.2 & 0 & 1.5 & 2 & 0.5 & 0 & 0.2 & 0 & 4.231 \\
\hline & & & & & & & & & & & & 3.367 \\
\hline & & & & & & & & & & & & 2.831 \\
\hline \multirow[t]{3}{*}{11} & 0 & 0.5 & 0.2 & 0 & 0.2 & 1.5 & 0 & 0 & 0 & 0.05 & 0 & 2.671 \\
\hline & & & & & & & & & & & & 3.723 \\
\hline & & & & & & & & & & & & 2.254 \\
\hline \multirow[t]{3}{*}{12} & 0 & 0.5 & 0.2 & 0.2 & 0.2 & 0 & 2 & 0 & 0.34 & 0 & 0.2 & 3.043 \\
\hline & & & & & & & & & & & & 2.547 \\
\hline & & & & & & & & & & & & 2.376 \\
\hline \multirow[t]{3}{*}{13} & 1.5 & 0.5 & 0 & 0 & 0 & 0 & 2 & 0.5 & 0 & 0.05 & 0.2 & 2.542 \\
\hline & & & & & & & & & & & & 3.849 \\
\hline & & & & & & & & & & & & 2.500 \\
\hline \multirow[t]{3}{*}{14} & 1.5 & 0.5 & 0 & 0.2 & 0 & 1.5 & 0 & 0.5 & 0.34 & 0 & 0 & 1.782 \\
\hline & & & & & & & & & & & & 1.695 \\
\hline & & & & & & & & & & & & 1.014 \\
\hline \multirow[t]{3}{*}{15} & 1.5 & 0.5 & 0 & 0 & 0.2 & 1.5 & 2 & 0 & 0.34 & 0 & 0 & 1.674 \\
\hline & & & & & & & & & & & & 1.558 \\
\hline & & & & & & & & & & & & 1.634 \\
\hline \multirow[t]{3}{*}{16} & 1.5 & 0.5 & 0 & 0.2 & 0.2 & 0 & 0 & 0 & 0 & 0.2 & 0.05 & 2.951 \\
\hline & & & & & & & & & & & & 2.565 \\
\hline & & & & & & & & & & & & 3.003 \\
\hline
\end{tabular}

\footnotetext{
${ }^{a}$ Found $\mathrm{N} \gamma$ Ps content in $\mathrm{mg}$ equivalent rubrofusarine/g of dry matter.
}

production is $84 \%$ of potato flakes and up to $16 \%$ of wheat bran, considering that olive pomace decreases massively the $\mathrm{N} \gamma \mathrm{Ps}$ obtained. This result indicates that $\mathrm{N} \gamma \mathrm{Ps}$ production is positively affected by the presence of polymeric sugars in the medium.

In SSF, the medium is an important factor to be taken into account, whether it was used as support of culture or substrate. In fact, as substrate, it has to efficiently provide microbial nutritional needs, and as support of culture, it has to possess favorable physical properties having consequence on water availability and allowing initial conidial anchorage, mycelial elongation in space and mass and heat transfers to occur over time [16]. The function difference and the essential aspect of each of these variables support and substrate - the fungus does not grow on a support alone - force that the two variables, which are of two distinct natures, must be used simultaneously, hence the utilization of a combined design. Obviously, when using natural byproducts, the distinction between support and substrate may be blurry, a solid susbtrate, because of its physical nature, participates as a support in the general texture of the medium. However, in this case, a ligneous byproduct as vine shoots or pine sawdust - rich in biopolymers recalcitrant to the enzymatic degradation by A. niger - acts mainly as a support: the fungus preferentially consuming the more easily metabolizable compounds. Although the porosity changes during the process, as fungal development may clog the empty spaces in the medium, the support

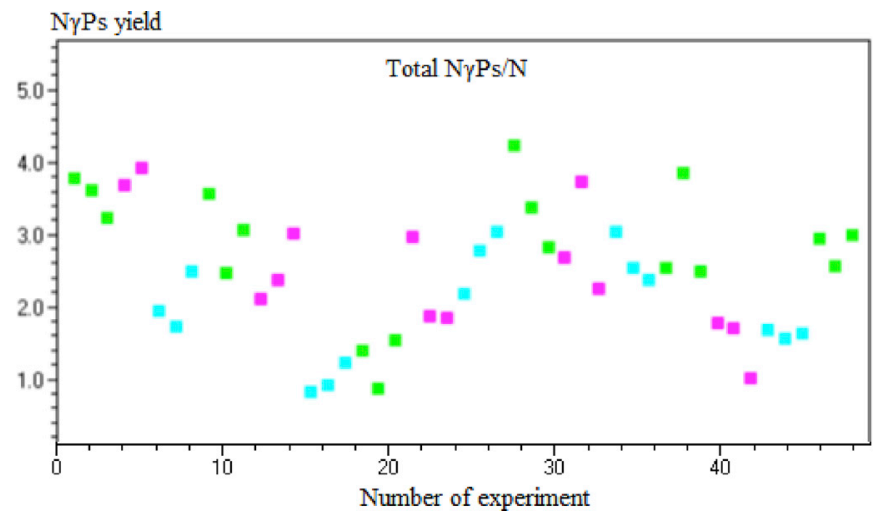

Fig. 6. Repeatability of the experiments for the medium chemical complementation. 
Table 7

Coefficient estimations of the model.

\begin{tabular}{ll}
\hline Coefficient & Value \\
\hline$\beta_{0}$ & 1.299 \\
$\beta_{1 \mathrm{~A}}$ & 1.024 \\
$\beta_{2 \mathrm{~A}}$ & -0.150 \\
$\beta_{3 \mathrm{~A}}$ & 0.336 \\
$\beta_{4 \mathrm{~A}}$ & -0.130 \\
$\beta_{5 \mathrm{~A}}$ & 0.355 \\
$\beta_{6 \mathrm{~A}}$ & 0.606 \\
$\beta_{7 \mathrm{~A}}$ & -0.327 \\
$\beta_{8 \mathrm{~A}}$ & 0.205 \\
$\beta_{9 \mathrm{~A}}$ & 0.247 \\
$\beta_{10 \mathrm{~A}}$ & -0.559 \\
$\beta_{10 \mathrm{~B}}$ & 0.251 \\
$\beta_{11 \mathrm{~A}}$ & 0.432 \\
$\beta_{11 \mathrm{~B}}$ & 0.475 \\
\hline
\end{tabular}

maintains the physical properties favorable for mass and heat transfers to occur, allowing for example the gaseous phase inside the interparticle void to be regenerated in oxygen while it is consumed by the fungus [17]. Following the same idea, substrate were selected, for their nutritional quality more than for their participation in the general texture of the medium. The vine shoots used in this study are previously extracted in ethanol to recover the polyphenols they contain. The fact that vine shoots show no difference with an inert ligneous support like pine sawdust suggests that they are correctly exhausted in compounds that may inhibit the fungal growth. It is also a good thing because it offers a way of valorization of an overproduced by-product in Southern France. Concerning substrate effects, N $\gamma$ Ps production is maximized with the presence of potato flakes, rich in starch, whereas olive pomace and in a smaller extent, wheat bran, reduce the obtained N $\gamma$ Ps content. Considering that wheat bran is richer in carbohydrates than olive pomace and contains starch, it appears that starch is an important compound to maximize the $\mathrm{N} \gamma \mathrm{Ps}$ production $[18,19]$. Cost and availability are the main factors considered to select suitable substrates for SSF. The opportunity for agro-industrial byproducts of low commercial value to be used as substrates in SSF is an important economic valorization approach [20].

However, in the literature, most of the optimization efforts are made on chemical complementation. In fact, the use of pure commercial compounds allows more precise studies to evaluate their effects on the physiology and metabolism of the fungus, ensures also a high level of repeatability and enhances the process consistency; on the other hand, using natural byproducts as cultural medium may increase the experimental variability between replicates leading to variations in the process performance, because of the complex nature of the substrate and thus an increase inherent disparateness of composition and texture and a higher batch-to-batch variations [21]. To go beyond this problem and reduce the heterogeneity that may exist between two stocks of the same byproduct, it is recommended to use byproducts from the same industrial sector that preferentially have the same standardized pre-treatments. In the study, good repeatability can be observed among because of a good inherent homogeneity of the chosen substrate. Of course, the use of a single solid matrix complemented with pure compounds may improve the repeatability of experiments, when compared to the use of multiple complex solid substrates. It is however possible to use a mixture of solid substrate and to have a good repeatability if the previous recommendations concerning the origin of the medium are respected.

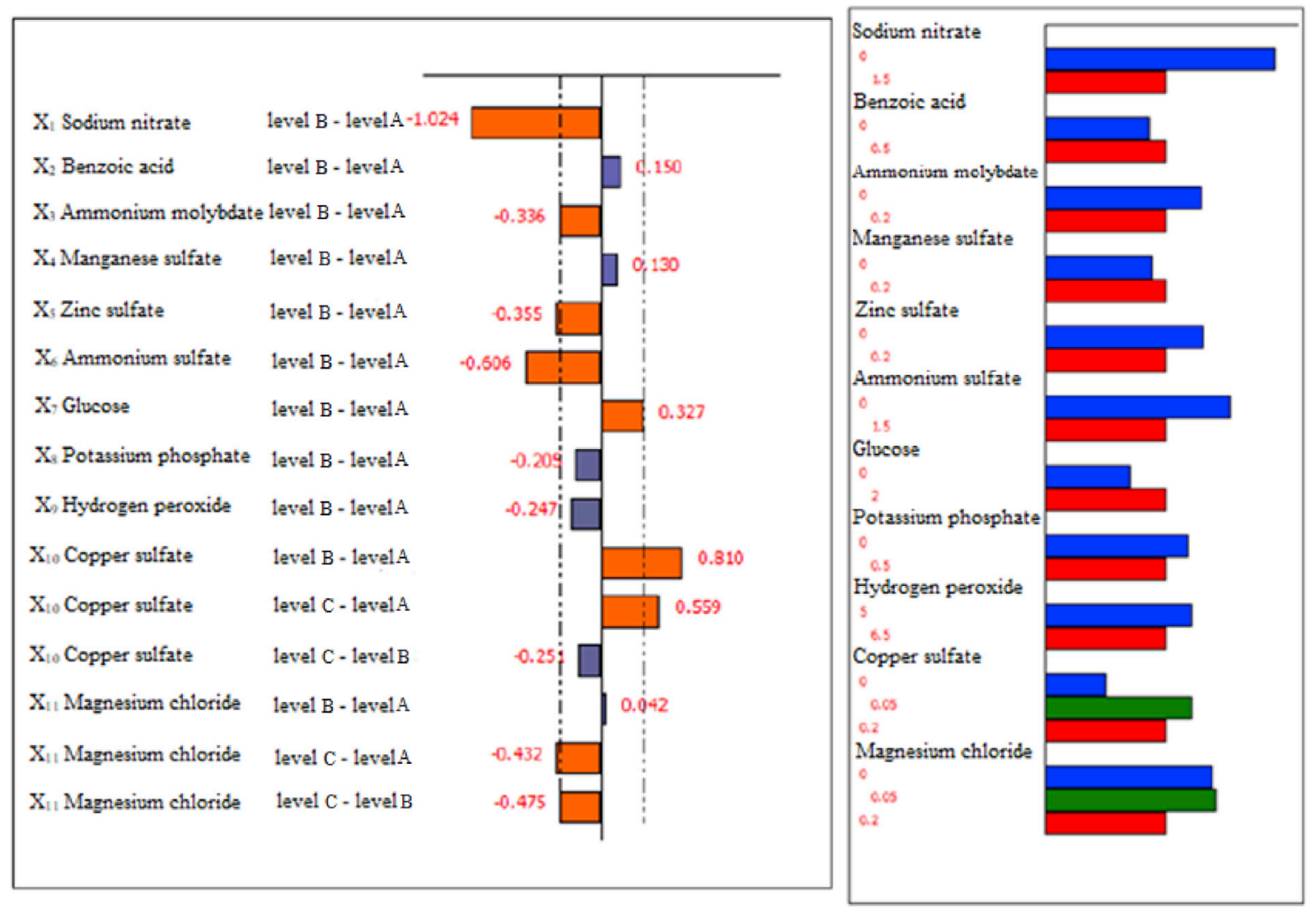

Fig. 7. On the left, the effect of each tested variable, orange color means that the variable has a significant effect on the response variable whereas blue means that the variable effect is comprised within the significance limits and is thus no significantly different from experimental error. On the right, in red the level B taken as reference and in blue and green, the effect on the response of the variation from level B to level A and from level B to level C, respectively. (For interpretation of the references to color in this figure legend, the reader is referred to the Web version of this article.) 


\subsection{Determination of the chemical complementation}

The 16 experiments have been performed and the results are given in Table 6.

The observation of the different replicates indicates that each experiment presents a higher variability than the previous experiment carried out for the solid medium definition (Fig. 6).

The estimations of the model coefficients using multilinear regression have been calculated (Table 7).

Statistical tools to identify active variable effects are used to generate effect plots (Fig. 7). In these plots, the signification of the coefficients is calculated from the variance which is represented by the vertical dotted line. The orange effects whether they are positive or negative, are the statistically significant ones. Seven variables have a significant effect on the response variable and among these, 2 variables have a positive effect.

Glucose $\left(\mathrm{X}_{7}\right)$ is scarcely significant and copper sulfate $\left(\mathrm{X}_{10}\right)$ has a positive effect at both level when it is present in the medium, although its intermediary level seems to maximize more the N $\gamma$ Ps production. Concerning this screening of chemical compounds for complementation, the use of an asymmetric matrix allows to study more precisely the effects of two factors, suspected to be critical in the N $\gamma$ Ps production: copper sulfate and magnesium chloride because those variables vary on 3 levels. Thus, though it is a screening study, it gives further information on what level is the more adapted to maximized the production. Initially, we started the fungus cultivation with a nonoptimized medium made of $50 \%$ of vine shoots and $50 \%$ of wheat bran that produced $1 \mathrm{mg}$ of $\mathrm{N} \gamma \mathrm{Ps}$ rubrofusarin/g dry matter. After two steps of optimization the secondary metabolites yield has been increased fourfold. More variables could also be studied to fully optimize the fermentation process, such as for example, physical parameters like temperature, aeration and water activity which are of critical importance in SSF [22].

\section{Conclusion}

The porosity between chemometrics and biotechnology helps to improve biotechnological processes such as SSF. Indeed, the diversity of tools offered by experimental design adapt itself very well to the constraints tied to the SSF process, themselves resulting from the high diversity of variable natures. A holistic vision of the optimization process in SSF, thus gathering the variables depending on their nature - whether they are solid or soluble compounds or physical parameters - and optimizing step by step from the definition of a complex solid medium to the right adapted chemical complementation and/or the right operative conditions like temperature and aeration can fully express the potential of the fungus following a simple strategy. In addition, this strategy of optimizing the best conditions of the previous design leads inevitably to a maximized result. If the final aim is the industrial scale-up of the production, it is important however, to define the adapted economic limit regarding the medium ingredients supply and the fermentation operative parameters.

\section{Acknowledgements}

Support from Vinovalie (CIFRE ANRT $N^{\circ}$ 2015/0027) is gratefully acknowledged.

\section{References}

[1] A. Pandey, Solid-state fermentation, Biochem. Eng. J. 13 (2003) 81-84.

[2] D. Berikten, M. Kivanc, Optimization of solid-state fermentation for phytase production by Thermomyces lanuginosus using response surface methodology, Prep. Biochem. Biotechnol. 44 (2014) 834-848.

[3] A. Sadaf, S.K. Khare, Production of Sporotrichum thermophile xylanase by solid state fermentation utilizing deoiled Jatropha curcas seed cake and its application in xylooligosachharide synthesis, Bioresour. Technol. 153 (2014) 126-130.

[4] C.R. Soccol, E. Scopel Ferreira da Costa, L.A.J. Letti, S.G. Karp, A.L. Woiciechowski, L.P. de Souza Vandenberghe, Recent developments and innovations in solid state fermentation, Biotechnol. Res. Innovat. 1 (2017) 52-71.

[5] L. Thomas, C. Larroche, A. Pandey, Current developments in solid-state fermentation, Biochem. Eng. J. 81 (2013) 146-161.

[6] N. Thadathil, A.K.P. Kuttappan, E. Vallabaipatel, M. Kandasamy, S.P. Velappan, Statistical optimization of solid state fermentation conditions for the enhanced production of thermoactive chitinases by mesophilic soil fungi using response surface methodology and their application in the reclamation of shrimp processing by-products, Ann. Microbiol. 64 (2014) 671-681.

[7] K. Aikat, B.C. Bhattacharyya, Optimization of some parameters of solid state fermentation of wheat bran for protease production by a local strain of Rhizopus oryzae, Acta Biotechnol. 20 (2000) 149-159.

[8] D. Deswal, Y.P. Khasa, R.C. Kuhad, Optimization of cellulase production by a brown rot fungus Fomitopsis sp. RCK2010 under solid state fermentation, Bioresour. Technol. 102 (2011) 6065-6072.

[9] P. Ellaiah, K. Adinarayana, Y. Bhavani, P. Padmaja, B. Srinivasulu, Optimization of process parameters for glucoamylase production under solid state fermentation by a newly isolated Aspergillus species, Process Biochem. 38 (2002) 615-620.

[10] D.P. Maurya, D. Singh, D. Pratap, J.P. Maurya, Optimization of solid state fermentation conditions for the production of cellulase by Trichoderma reesei, J. Environ. Biol. 33 (2012) 5-8.

[11] T.A. Pham, J.J. Kim, K. Kim, Optimization of solid-state fermentation for improved conidia production of Beauveria bassiana as a mycoinsecticide, Mycobiology 38 (2010) 137.

[12] S. Senthilkumar, B. Ashokkumar, K. Chandraraj, P. Gunasekaran, Optimization of medium composition for alkali-stable xylanase production by Fxn 1 in solid-state fermentation using central composite rotary design, Bioresour. Technol. 96 (2005) 1380-1386.

[13] J.A. Cornell, Experiments with Mixtures: Designs, Models, and the Analysis of Mixture Data, third ed., Wiley, New York, 2002.

[14] V. Fedorov, Theory of Optimal Experiments, Academic Press, 1972.

[15] S. Addelman, Symmetrical and asymmetrical fractional factorial plans, Technometrics 4 (1962) 47-58, 1.

[16] D. Mathieu, J. Nony, R. Phan-Tan-Luu, NEMROD-w Software, LPRAI, Marseille 1. In These Studies, the Generation and the Data Treatment of the Designs Were Performed Using the Experimental Design Software Nemrod-w, 2000.

[17] A. Pandey, C.R. Soccol, D. Mitchell, New developments in solid state fermentation: I-bioprocesses and products, Process Biochem. 35 (2000) 1153-1169.

[18] L.P. Ooijkaas, F.J. Weber, R.M. Buitelaar, J. Tramper, A. Rinzema, Defined media and inert supports: their potential as solid-state fermentation production systems, Trends Biotechnol. 18 (2000) 356-360.

[19] S. Dermeche, M. Nadour, C. Larroche, F. Moulti-Mati, P. Michaud, Olive mill wastes: Biochemical characterizations and valorization strategies, Process Biochem. 48 (2013) 1532-1552.

[20] O.O. Onipe, A.I.O. Jideani, D. Beswa, Composition and functionality of wheat bran and its application in some cereal food products, Int. J. Food Sci. Technol. 50 (2015) 2509-2518.

[21] H. Demir, C. Tar1, Valorization of wheat bran for the production of polygalacturonase in SSF of Aspergillus sojae, Ind. Crop. Prod. 54 (2014) 302-309.

[22] E. Oriol, M. Raimbault, S. Roussos, G. Viniegra-Gonzalez, Water and water activity in the solid-state fermentation of cassava starch by Aspergillus Niger, Appl. Microbiol. Biotechnol. 27 (1988) 498-503. 